\title{
Citation Characteristics and Intellectual Acceptance of Scholarly Monographs
}

\section{Rong Tang}

The present study investigates citations to 750 randomly selected scholarly monographs in disciplines of religion, history, psychology, economics, mathematics, and physics. The objective of the study is to understand distributions of citations to scholarly monographs in various disciplines, to explore disciplinary difference in the citing of books, and to compare citations to monographs with previous results on citations to journal articles. The data revealed interesting citation patterns and aging effects that are in several aspects different from citation data based on the journal literature. While the distribution trend of monographic uncitedness is similar to that of journals across the disciplines, the noncitation ratios are much lower than what has been reported about journal citations. Half-life measures of scientific monographs are greater than those in the humanities and social sciences; this contradicts previous findings. Citation frequency and Price's Index vary from discipline to discipline, and the most significant linear contract occurred between disciplines of religion, history, and economics as one group and psychology, mathematics, and physics as another. When using periods of intellectual acceptance as the unit of analysis, significant disciplinary differences emerged both in terms of citation frequency and the number of books cited. Significant differences also appeared between earlier periods of intellectual acceptance that are within the first 10 years following the original publication year and longer ages of survival that are beyond 10 years.

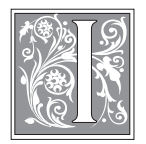

$n$ citation research, it is generally acknowledged that the disciplines of science, social science, and the humanities employ different forms of publications as their means of scholarly communication. Specifically, scientific disciplines use journals frequently for their format of research output, whereas social science and humanities researchers use books for a major portion of their scholarly endeavors. Several empirical studies have shown that there is little correlation between the citation patterns to monographic literature and those of journal literature. ${ }^{1}$ Researchers further indicate that one of the limitations of citation databases produced by the Institute of Scientific Information (ISI) is that they are oriented almost exclusively to citations in journal publications. Consequently, warnings have been issued against blindly using the ISI citation data. ${ }^{2}$

Rong Tang is Assistant Professor at the Graduate School of Library and Information Science of Simmons College; e-mail: rong.tang@simmons.edu. 
The present study investigates citations to scholarly monographs in the disciplines of religion, history, psychology, economics, mathematics, and physics for the purpose of exploring distributions of citations to monographic literature. These six disciplines were selected based on their academic domains, and the relatively high book production rates (over 10,000 items for each discipline selected at the time of searching) resulted from searching dialog LC MARC-Books database. The intent was to explore general obsolescence and recency patterns of citations to monographs in six academic disciplines and to further identify domain or disciplinary differences in citation counts, measured against the periods of intellectual acceptance (as per LindholmRomantschuk and Warner ${ }^{3}$ ).

\section{Disciplinary Roles in Monographic Citations}

Numerous studies have demonstrated that monographs play an essential role in the scholarly communication of social sciences and humanities. As Line points out, in the humanities and social sciences, "it is known that journals constitute less than half of the research literature of most disciplines." ${ }^{4}$ Weintraub ${ }^{5}$ declares that "humanists are probably the most bookbound creatures in the world of scholarship. ${ }^{\prime 6}$ In a review of social science citations, Broadus outlined findings of earlier studies that suggest the proportion of citations to monographs in the social sciences and humanities are much higher than in hard sciences. ${ }^{7}$ For example, 48 percent to 51 percent of citations in economics are to monographs, whereas chemists only use 5 percent monographs and physicists 8 percent. Earle and Vickery concluded that books account for 46 percent of the overall citations to U.K. social science literature, whereas only 12 percent of the citations in natural science were to books. ${ }^{8}$ Small and Crane found 0.9 percent of cited items in journal articles of high energy physics were books, 15 percent in psychology, 25 percent in economics, and 39 percent in sociology. ${ }^{9}$ Bonzi's study revealed that books only occupied 6 percent of Syracuse faculty's total productivity in science, ${ }^{10}$ whereas 17 percent to 24 percent of work by humanities and social science faculty were books or chapters. In examining University of Texas undergraduate term papers, Magrill and St. Clair discovered that 68 percent and 57 percent of students in humanities and social sciences cited books, as compared to 21 percent in sciences. ${ }^{11}$

Among the humanities disciplines, the field of literature reportedly has the highest percentage, with an average of 70 percent of books cited. The book citation rates vary from 78.8 percent in the field of literary movements, ${ }^{12} 75$ percent in English literature, ${ }^{13} 72.2$ percent in British and American literary studies, ${ }^{14}$ to 64 percent in American literature. ${ }^{15}$ However, philosophy and American studies have slightly higher portions of citations to the journal literature. ${ }^{16}$ Overall, a majority of the research data confirms an observation made by Hicks ${ }^{17}$ that "journals represent a more scientific type of research and books a more humanities type of scholarship." ${ }^{18}$ Nevertheless, the mainstream citation research has been biased toward the data based on journal publications, as indicated by a number of researchers. ${ }^{19}$

The neglect of monographic literature in bibliometric research has motivated researchers to examine the impact of monographs. In studying a bibliography of Sociology of Scientific Knowledge (SSK), Hicks and Potter discovered that, on average, a book received 5.7 citations, while a journal received only $1.2 .{ }^{20} \mathrm{Cle}-$ mens, Powell, Mcllwaine, and Okamoto compared citations to sociology journals and books and found that book citations outperformed journal citations by a ratio of $3: 1{ }^{21}$ This finding was supported by Lindholm-Romantschuk and Warner's study, which showed a 2.6:1 citation ratio of books to journals in sociology, 7.7:1 in philosophy, and 2.4:1 in economics. ${ }^{22}$ In the domain of humanities studies, Stern found citations to literary monographs far 
TABLE 1

Uncitedness Index by Domains and Disciplines (Source: Data From Hamilton ${ }^{72}$ )

\begin{tabular}{|l|c|c|c|c|c|c|}
\hline \hline Domains & \multicolumn{2}{|c|}{ Science } & \multicolumn{2}{c|}{ Social Science } & \multicolumn{2}{c|}{ Arts \& Humanities } \\
\hline Uncitedness ratio & \multicolumn{2}{|c|}{$47.40 \%$} & \multicolumn{2}{c|}{$74.70 \%$} & \multicolumn{2}{c|}{$98.00 \%$} \\
\hline Disciplines & Physics & Math & $\begin{array}{l}\text { Social } \\
\text { Psych }\end{array}$ & Business & History & Religion \\
\hline Uncitedness ratio & $36.7 \%$ & $55.5 \%$ & $35.4 \%$ & $76.6 \%$ & $95.50 \%$ & $98.20 \%$ \\
\hline
\end{tabular}

exceed those to journal articles. ${ }^{23}$ In addition, a number of studies provided evidence suggesting monographic citation patterns differ remarkably from journal citations. Line investigated monographic and journal references and noticed that, within each type of source material, citations occur most frequently to publications within their own form. ${ }^{24}$ Forty-seven percent of journal references were to journals, and 51 percent of monograph references were to books. Based on their observation of sociology monographic and journal samples, Cronin, Snyder, and Atkins claim that "there may be two populations of highly cited authors, one which is highly cited in monographs and one which is highly cited in journals." 25 Hicks also suggests that book and journal publishing may represent "two worlds of literature." 26 This paper focuses on citations to monographic publications, an attempt to examine the extent to which the previous citation research built on journal citations bears the similarity to citations to scholarly monographic literature.

\section{Disciplinary Differences in Citedness and Citation Aging}

One aspect of citation analysis on disciplinary differences is the issue of uncitedness. Uncitedness, also called noncitation, is used to describe a situation in which a publication has not received any citation during a given period of time. ${ }^{27}$ Inconsistent reports of uncited ratios were found among studies on uncitedness of scholarly work in various disciplines. Price estimates that 10 percent of scientific publications are never cited, ${ }^{28}$ whereas Garfield's finding was 3.9 percent. ${ }^{29}$ Published in Science from late 1990 to early 1991, a heated round of discussions centered around the high noncitation ratios of science, a 55 percent in the five years after they were published..$^{30}$ Another study, authored by Hamilton, includes a very detailed set of statistics of an uncitedness index produced by Pendlebury from ISI. ${ }^{31}$ For papers published in 1984 and the citations they cumulated through 1988 , science has the lowest uncitedness average $(47.4 \%)$, whereas social sciences fall a distant second, holding 74.7 percent of uncitedness rate. The humanities scholarship has the highest ratio, 98 percent. Note that the journal article is the form of publication used in Pendlebury's analysis (table 1).

In terms of the degree of noncitations in individual disciplines, the uncitedness average is the lowest for social psychology (an exception in the social sciences), followed by physics, mathematics, business, history, and religion. History and religion were well above 95 percent, which is strikingly high. Since most of the uncited data are drawn from citation counts to journal papers, it is therefore valuable to obtain uncitedness ratios to monographic literature and then to cross-examine them with the statistics presented in the previous research.

Aging effect, represented by measures of half-life and Price's Index, is another factor to consider when investigating disciplinary characteristics of citations. Half-life is a measure of obsolescence of scholarly literature, which is obtained by subtracting the publication year of the source documents from the median publication year of citing documents. ${ }^{32}$ Earle and Vickery's study suggests that the halflife of citations to science periodicals was 
roughly seven years, ${ }^{33}$ although other researchers discovered that for physics the half-life is less than five years. ${ }^{34}$ Earle and Vickery found that half-lives for all forms of social science publications range from seven (as in economics) to 37 years (as in the study of social customs). ${ }^{35}$ The half-life in Humanities scholarship is perceived as higher, and some papers have provided supporting data. For instance, Wiberley discovered that over half of citations to literary studies and art scholarship were to works published more than 20 years before their own publications. ${ }^{36}$ Budd indicated that more than half of the cited items among the references of 253 source items in American literature were older than 16 years. ${ }^{37}$

As a measure of citation recency, Price's Index calculates the proportion of the number of citations that are no more than five years old over the total number of citations an item receives. ${ }^{38}$ Price's Index was found to be above 50 percent for science, ${ }^{39}$ between 40 percent and 43 percent for social science,,$^{40}$ and less than 21 percent for humanities disciplines. ${ }^{41}$ Budd found that a substantial proportion of references in scientific disciplines such as physics, chemistry, or microbiology are five years old or less. ${ }^{42}$ Furthermore, "the very limited use of older materials in the sciences is very evident." ${ }^{43}$ Small and Crane discovered that the order of the recency score was physics, psychology, economics, and then sociology. ${ }^{44}$ Line's examination on date distribution of journal and monograph citations revealed that in most disciplines, journal references decay faster than monographic references. ${ }^{45}$ Specifically, in economics, it takes 20 years for 90 percent of references from journals to occur, and 28 years for books. In psychology, it takes 23 years for journals and 30 years for books. Line further indicates that in economics, "monographs make a higher proportion of references to both the most recent and the least recent years." 46

The aging effect of scholarly publications can also be examined through the comparison of the citations as a time unit that is based on the citation year following the publication year. After separating the monographs of philosophy, sociology, and economics into core and noncore classes, Lindholm-Romantschuk and Warner found that the human and social sciences showed a relatively slow decline into obsolescence in comparison with natural science. ${ }^{47}$ The authors classified the year following publication into two major periods of knowledge diffusion: initial reception and intellectual survival. Initial reception is "the period of three calendar years from publication (including the year of publication)"; $; 8$ and intellectual survival is the number of years after the initial reception..$^{49}$ The authors claimed that there is evidence of a correlation between the initial impact and subsequent reception.

To summarize, scientific publications have the lowest degrees of uncitedness, shortest time spans of half-lives, and the highest levels of recency. The intellectual acceptance patterns within monographic literature could vary by discipline. In this light, the first component of the present study is to verify whether previous findings on journal citation patterns also describe distribution of citations to monographs. Following that, the aspect of aging or intellectual survival is examined through coding citation data by year from publication and periods of intellectual acceptance.

\section{Hypotheses and Research Questions}

The hypothesis of the study is that the general distribution patterns of citations to monographic literature in the six selected disciplines are similar to what have been reported as the characteristics of citations to journal literature. This study analyzes specifically the aspects of overall citation counts, noncitation ratios, halflives, and Price's Index of the citations to scholarly monographs in the disciplines of religion, history, psychology, economics, mathematics, and physics. The study also addresses the following two research questions: 
1. Are there significant domain or disciplinary differences in the distribution of citations to monographs, half-lives, and Price's Index?

2. If conditioned on the periods of intellectual acceptance, are there significant differences among disciplines in terms of citation frequency and number of books cited per period?

\section{Methods}

The data collection involved generating a random sample of 125 monographs in religion, history, psychology, economics, mathematics, and physics as source documents and identifying citations to the total of 750 source books. The sample size of 125 within each discipline was determined primarily based on the feasibility of data processing workload. The reader is forewarned that such a sample size is generally not viewed as sufficiently representative of a population of over 10,000.50 Considering that the 125 randomly selected books in each discipline would be used as the source items to which a greater number of citations are targeted, current sample was believed to be a good size for exploratory purposes.

The sample data of the study was collected in May of 2004 through two steps. Step 1 included searching LC MARC-Books database on Dialog (file 426) for monographic publications in six disciplines. The database provides access to a comprehensive, worldwide collection of books cataloged by the Library of Congress since $1968 .{ }^{51}$ The benefit of searching such a database includes the capability of limiting book items to a particular discipline in the "Descriptor" field and then refining it with the relevant LC call number. Specifically, the search began by limiting all searches to nonfiction items that are published prior to 2004. The items were restricted to each of the six disciplines through searching the discipline name and limiting the items by LC call number categories. Conference proceedings were excluded. The call number category for each discipline and the total number of monographs retrieved are listed in table 2. Following this, 125 items were randomly selected for each discipline. The full bibliographic records of the sample were retrieved and saved as records of source documents.

The second step was to search ISI citation databases for citations to these monographs. All citation databases - Science Citation Index (Dialog files 434 and 34), Social Science Citation Index (Dialog file 7), and Arts and Humanities Citation Index (Dialog file 439) - were searched to check the citations to a given monograph. These databases are international, multidisciplinary citation indexes to the literature of the science, social science, and arts and humanities, produced by the Institute for Scientific Information (ISI $\left.{ }^{\circledR}\right) .^{52}$ The limitations of the databases include its orientation toward journal literature ${ }^{53}$ and its underrepresentation of non-English publications. ${ }^{54}$ The decision to use the ISI citation databases to create sample data for the study was based on the fact that, despite their weaknesses, the three citation databases are currently the most comprehensive and up-to-date citation indexes covering scholarly publications in the United States.

Upon checking each citing item, the recorded data sheet included information about the citing documents. Source items

\begin{tabular}{|c|c|c|}
\hline \multicolumn{3}{|c|}{$\begin{array}{c}\text { TABLE } 2 \\
\text { LC Call Number Used and Total } \\
\text { Number of Items Retrieved (May 2004) } \\
\text { From the LC MARC Database }\end{array}$} \\
\hline Disciplines & $\begin{array}{c}\text { LC Call Number } \\
\text { Category }\end{array}$ & $\begin{array}{c}\text { Total Items } \\
\text { Retrieved }\end{array}$ \\
\hline Religion & $\mathrm{BL}$ & 11,810 \\
\hline History & $\mathrm{D}$ & 30,085 \\
\hline Psychology & $\mathrm{BF}$ & 19,770 \\
\hline Economics & $\mathrm{HB}$ or $\mathrm{HC}$ & 17,267 \\
\hline Mathematics & QA & 20,250 \\
\hline Physics & QC & 11,020 \\
\hline
\end{tabular}




\begin{tabular}{|c|c|c|c|c|c|c|c|}
\hline \multicolumn{8}{|c|}{$\begin{array}{c}\text { TABLE } 3 \\
\text { Coding of Periods of Intellectual Acceptance }\end{array}$} \\
\hline 1 & 2 & 3 & 4 & 5 & 6 & 7 & 8 \\
\hline $\begin{array}{l}0.5-2 \\
\text { years }\end{array}$ & $\begin{array}{l}3-5 \\
\text { years }\end{array}$ & $\begin{array}{l}6-10 \\
\text { years }\end{array}$ & $\begin{array}{l}11-30 \\
\text { years }\end{array}$ & $\begin{array}{l}31-50 \\
\text { years }\end{array}$ & $\begin{array}{l}51-99 \\
\text { years }\end{array}$ & $\begin{array}{l}100-199 \\
\text { years }\end{array}$ & $\begin{array}{l}200-210 \\
\text { years }\end{array}$ \\
\hline
\end{tabular}

that received a high quantity of citations were given extra attention and were set up with separate coding sheets for citing documents. Data coding was performed on SPSS to create the half-life measure and Price's Index value for each cited source document. Year from publication was coded into eight periods of intellectual acceptance, with period one covering the same year and two years after the original publication (the "initial reception" period in Lindholm-Romantschuk and Warner ${ }^{55}$ ). The periods that are beyond the initial reception were operationally defined for this analysis, based in part on timeline mapping of citations to monographs in philosophy, sociology, and economics included in Lindholm-Romantschuk and Warner's study. ${ }^{56}$ The exact coding scheme for various periods is listed in table 3 .

\section{Data Analysis}

Data analysis was performed at both descriptive and inferential levels. The independent variable for this project was academic discipline, with periods of intellectual acceptance added as a second independent variable for MANOVA. Dependent variables of the study included various computed counts such as total number of citations, half-life measures, Price's Index, and the number of books cited per year following publication. Two series of inferential statistics tests were performed: (1) ANOVA for disciplinary differences in citation counts, half-life, and Price's Index; and (2) MANOVA for disciplinary differences in citation counts and number of books cited with periods of intellectual acceptance as the unit of analysis.

\section{Results}

The presentation of results will progress from reports of descriptive data to inferential statistical tests on the significance and contrasts of disciplinary difference among periods of intellectual acceptance.

\begin{tabular}{|c|c|c|c|c|c|c|}
\hline \multicolumn{7}{|c|}{$\begin{array}{c}\text { TABLE } 4 \\
\text { Citation Distribution of Monographs }\end{array}$} \\
\hline $\begin{array}{l}\text { Academic } \\
\text { Disciplines }\end{array}$ & $\begin{array}{l}\text { Average } \\
\text { Citation* }\end{array}$ & $\begin{array}{l}\text { Average } \\
\text { Source } \\
\text { Publication } \\
\text { Year }\end{array}$ & $\begin{array}{l}\text { Average } \\
\text { Citation } \\
\text { Year }\end{array}$ & Half-Life & $\begin{array}{l}\text { Price's } \\
\text { Index** }\end{array}$ & $\begin{array}{l}\text { Uncitedness } \\
\text { Ratio }\end{array}$ \\
\hline Religion & 4.30 & 1988 & 1994 & 8.76 & 0.44 & $59 \%$ \\
\hline History & 3.24 & 1986 & 1994 & 7.13 & 0.29 & $52 \%$ \\
\hline Psychology & 48.14 & 1988 & 1994 & 7.15 & 0.41 & $46 \%$ \\
\hline Economics & 6.52 & 1986 & 1992 & 9.38 & 0.33 & $45 \%$ \\
\hline Math & 38.40 & 1984 & 1995 & 9.17 & 0.47 & $41 \%$ \\
\hline Physics & 32.52 & 1983 & 1994 & 13.07 & 0.48 & $35 \%$ \\
\hline \multicolumn{7}{|c|}{$\begin{array}{l}\text { Note: Significant differences were found between disciplines both in terms of citation } \\
\text { counts and Price's index. } \\
* p<.01 \text {. } \\
* * p<.05 \text {. }\end{array}$} \\
\hline
\end{tabular}




\section{Citation Distributions, Uncitedness, and Aging Effect}

Table 4 displays the mean frequency of citations to the six disciplines, the average publication year of the source monographs, the average publication year of citations, half-lives, Price's Index, and uncitedness ratios. Among the six disciplines, psychology received the highest number of citations, with a total of more than 6,000 citations and an average of 48.1 citations per monograph. Mathematics and physics also received high numbers of citations for their monographs. Economics, religion, and history received low citations, with history receiving an average of 3.2 citations per item. The disciplinary differences in citation counts are significant $(p<.01)$. The average publication year $(p=.24)$ and citation year $(p=.63)$ of each discipline are not significantly different from one another. Half-life scores, however, are different from reports of previous research. The most obvious difference is that of physics, which has the longest half-life (13.1) among the six disciplines, as opposed to the previous report of less than five years. Half-lives of humanities disciplines are the shortest, which contradicts the general expectation that humanities literature has the longest half-lives among the three domains. The citations to monographs in this study have the exact opposite half-life values to what was reported about journal citations. Recall Earle and Vickery's results of an average of seven years for scientific disciplines. Earle and Vickery also found that the half-life for economics is seven and for social psychology is eight, which is somewhat closer to the results here. ${ }^{57}$ Note that from the ANOVA test, the differences among disciplinary half-lives were not significant $(p=.34)$; neither are differences of representative domains $(p=.22)$.

Values of Price's Index bear some similarity to results of previous studies. Specifically, scientific disciplines such as physics and mathematics hold the highest proportion of recency, whereas history has the lowest. Religion, however, has a surprisingly high recency proportion, which is in great contrast with Price's estimate of less than 21 percent for humanities scholarship. ${ }^{58}$

The last column of table 4 consists of the uncitedness ratio for each discipline. The highest uncited disciplines were those of humanities studies, specifically history and religion. The citations to monographs sustained a much lower degree of noncitation, compared to Hamilton's journal noncitation at 98.2 percent for religion and 95.5 percent for history. ${ }^{59}$ The noncitation for social science disciplines in this study was 41 percent for psychology, which is similar to Hamilton's 35.4 percent for social psychology; $; 0$ and 46 percent for economics, which differs greatly from Hamilton's social science average of 74.7 percent. ${ }^{61}$ Physics had the lowest uncitedness ratio of 35 percent in this study, similar to Hamilton's 36.7 percent. ${ }^{62}$ Books in mathematics apparently received more citations, with 45 percent of noncitations, as opposed to 55.5 percent in mathematical papers. Recall that Clemens et al. discovered that books are generally three times more cited in sociology, ${ }^{63}$ and this is confirmed in several disciplines from the data here. Physics, however, has a rather similar degree of uncitedness across the two forms of publications.

\section{Disciplinary Differences in Citation Patterns and Periods of Acceptance}

Disciplinary differences were tested on two levels: (1) differences of disciplinary citation patterns based on citations to each source document; and (2) disciplinary differences as measured by total citations and cited book counts conditioned on the year from publication. For the first aspect, one-way ANOVA was performed with citation counts, half-lives, and Price's Index values as dependent variables. Also embedded in the ANOVA were contrast tests between the three domains and a contrast test between psychology, mathematics, and physics as one group, and the remaining three as the other. The test yielded significant results for total citations by discipline $(\mathrm{F}=3.329, \mathrm{df}=5, p<0.01)$ 


\begin{tabular}{|l|c|c|}
\hline \multicolumn{3}{|c|}{ TABLE 5 } \\
Peak Year of Citations \\
\hline \hline Discipline & $\begin{array}{c}\text { Peak Year } \\
\text { (from the } \\
\text { Publication Year) }\end{array}$ & $\begin{array}{l}\text { Average } \\
\text { Citations }\end{array}$ \\
\hline Religion & 2 & 75 \\
\hline History & 2 & 59 \\
\hline Psychology & 7 & 266 \\
\hline Economics & 1 & 92 \\
\hline Mathematics & 14 & 264 \\
\hline Physics & 9 & 206 \\
\hline
\end{tabular}

between social science and science was not significant by citation frequency, and Price's Index was not significantly different between the humanities and social science.

Disciplinary differences were further examined through coding publication year of citing items into year from publication and then further into periods of intellectual acceptance. Table 5 includes the data of the peak year from publications for each discipline, and during that year period, the average citation reached the highest level. Figure 1 presents citation frequency and Price's Index by discipline ( $\mathrm{F}=2.321$, $\mathrm{df}=5, p<0.05)$. The half-life measures are not significant, which means the obsolescence rate of monographs in the six disciplines is not statistically different from one another. Among the four linear contrasts in ANOVA, the most significant level of difference for both citation frequency and Price's Index was found in the contrast of psychology, mathematics, and physics as one group, and economics, history, and religion as another group. The contrast of each discipline by the year from publication. It is apparent that the peak time of citations for six disciplines all occurred within the first 20 years from the time a given book was published. Interestingly, scientific disciplines such as Mathematics and Physics peaked relatively late compared to humanities disciplines. Religion and history reached their highest citation amount within the first five years from the publication whereas psychology, physics, and mathematics did not receive their cita-

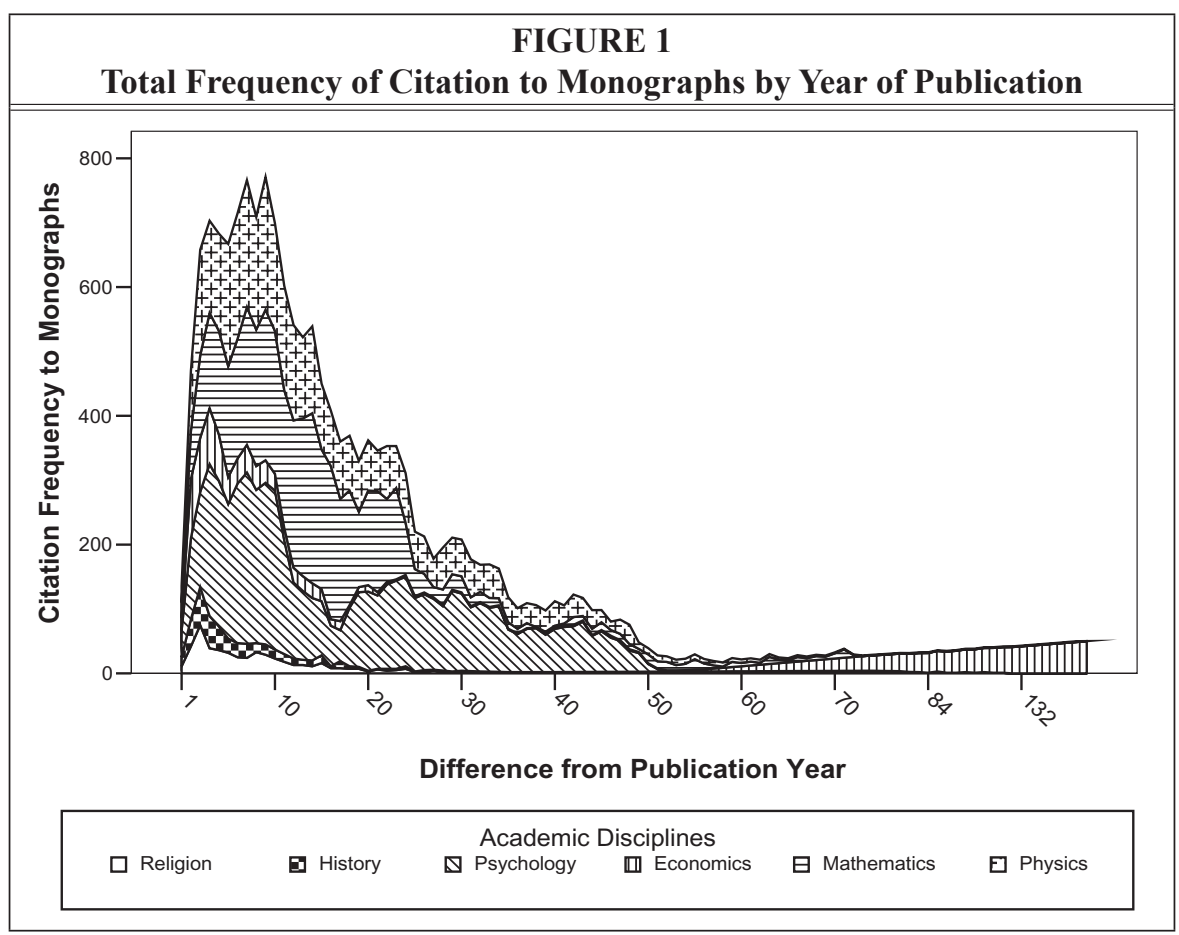


tion heyday until more than six years after the publication. The books in the Economics data sample reached their greatest citation amount within one year of the publication.

Table 6 lists the period of intellectual acceptance during which each discipline received the highest average citation. Figure 2 illustrates the citation distribution within each period of acceptance. The highest period of intellectual acceptance for both religion and history is the initial reception period. Economics fell in period two, which is the

\begin{tabular}{|l|c|c|c|}
\hline \multicolumn{4}{|c|}{$\begin{array}{c}\text { TABLE 6 } \\
\text { Peak Periods of Intellectual Acceptance } \\
\text { by Citation Frequency }\end{array}$} \\
\hline \hline Discipline & $\begin{array}{c}\text { Peak } \\
\text { Period }\end{array}$ & $\begin{array}{c}\text { Average } \\
\text { Citations }\end{array}$ & $\begin{array}{c}\text { No. of } \\
\text { Books Cited }\end{array}$ \\
\hline Religion & 1 & 42.67 & 19 \\
\hline History & 1 & 38.33 & 19 \\
\hline Psychology & 3 & 250.00 & 24 \\
\hline Economics & 2 & 67.00 & 23 \\
\hline Mathematics & 3 & 213.60 & 26 \\
\hline Physics & 3 & 188.00 & 26 \\
\hline
\end{tabular}
year range of three to five years. Finally, psychology, mathematics, and physics all have the third period as their prime period, which is the year period of six to ten years following the source publication.

Figure 3 displays a slightly different pattern when looking at the number of books cited within each period of intellectual acceptance. In terms of the number of books cited, the peak period for religion, history, and economics is the

initial reception period, whereas period two (year three to five) is the highest point for psychology, mathematics, and physics. Citations to both history and religion books end at period five, and the remaining disciplines virtually stop at period six. The in-degree citation data of economics monographs confirms with Line's observation on the out-degree citation of economics monographs. ${ }^{64}$ There are citations at both extremes of the most recent and least recent years. For all dis-

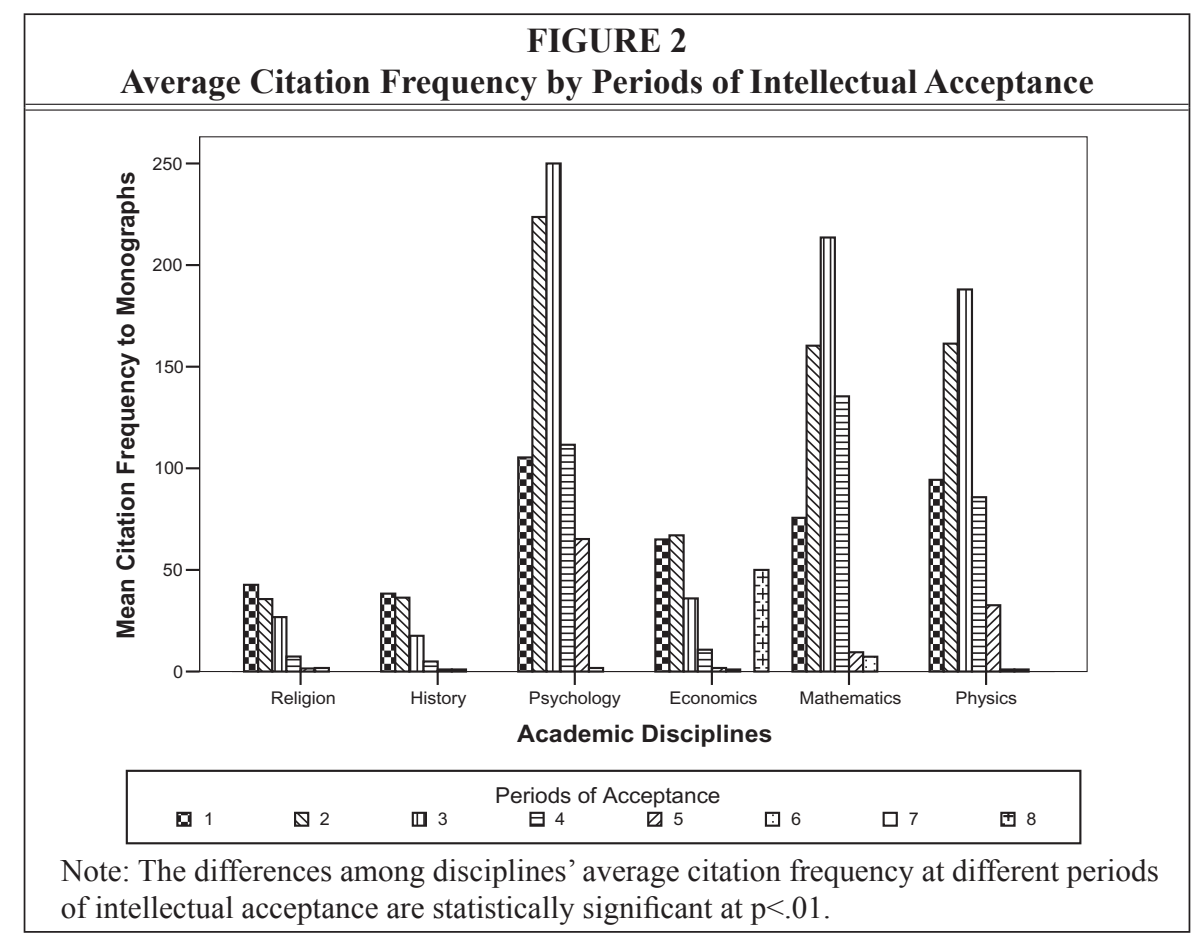




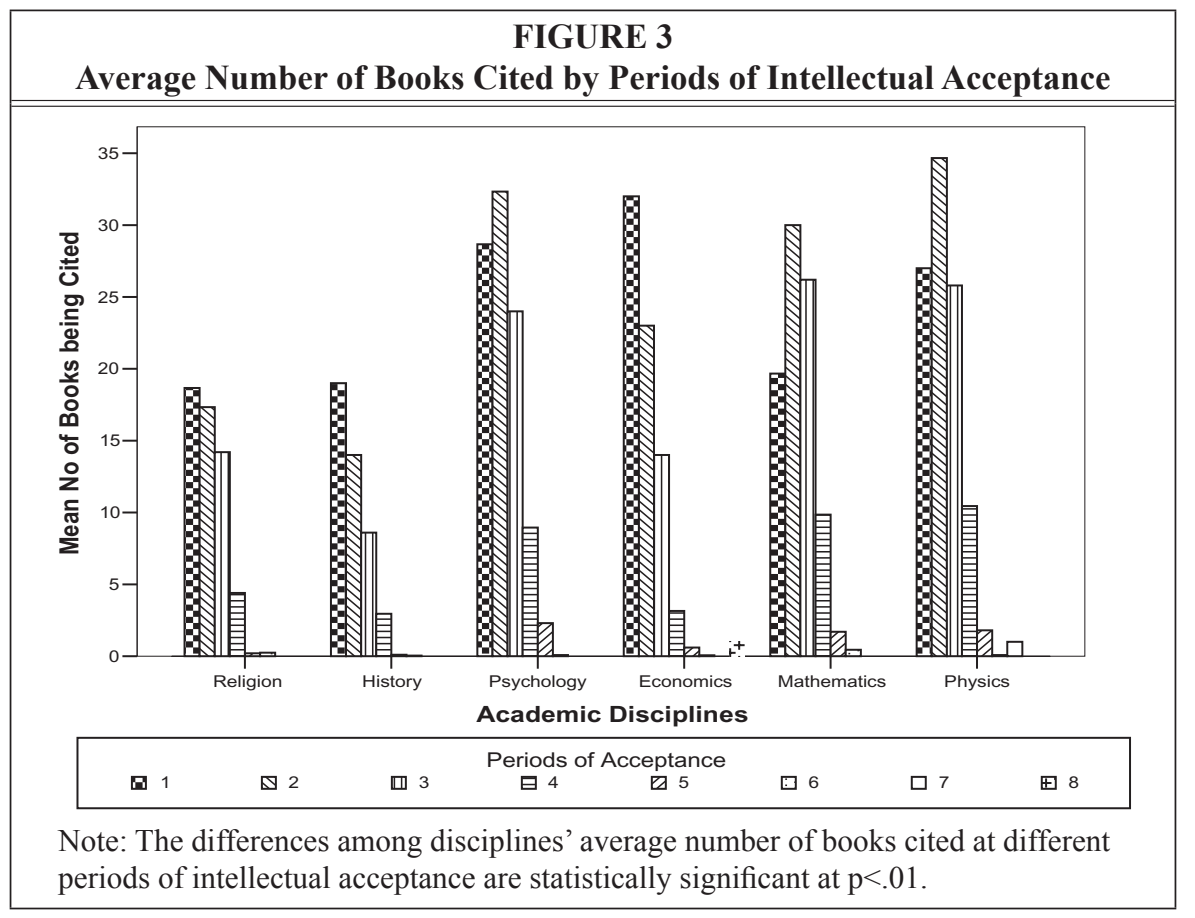

ciplines, the number of books cited after period four is no more than two.

Multivariate Analysis of Variance (MANOVA) was conducted to test the disciplinary difference of citation counts and number of books cited based on the periods of intellectual acceptance. The test produced significant results for both total number of citations $(\mathrm{F}=36.7$, $\mathrm{df}=37, p<0.00)$ and number of books cited $(\mathrm{F}=35.9, \mathrm{df}=37, p<0.00)$. Simple contrasts of academic disciplines revealed that in terms of citation distribution and number of books cited, the differences between religion and psychology, religion and mathematics, and religion and physics are all significant. On the other hand, there is no significant difference between religion and history or between religion and economics. The contrasts between citation counts on periods of intellectual acceptance suggest significant differences between period one and periods four, five, six, and seven; however, the differences between period one and periods two $(p=.93)$, three $(p=.17)$, and eight $(p=.66)$ are not significant. Figure 2 shows the dura- tion from period one to two to three is generally the rising period of intellectual acceptance for scholarly monographs of most disciplines, and the decline starts mostly at period four, which is from year 11 to year 30. The findings from Hicks and Potter indicating citations of most disciplines increase at six years after publication ${ }^{65}$ was confirmed in this study. The length of intellectual acceptance mostly ends at period six, which is beyond 50 years of age. In terms of number of books cited, significant differences were found between period one and all the rest of the periods $(p=.01)$. When measured by number of books cited, the decline period starts at period four and by period five or the 31st year following publication or beyond, most of the disciplines have fewer than two books cited.

\section{Discussion and Conclusion}

The present study strives to fill the research gap in citation research concerning distribution of citations to scholarly monographs. In particular, the study provides valuable data and interesting 
insights outlining the shared and unique characteristics of citations to monographs, comparing to patterns of citations to journal literature established by the previous research. Specific statistics regarding the citation counts, half-lives, Price's Index, and uncitedness of citations to monographs in six disciplines were generated. Disciplinary comparisons were made in regard to the overall citation distribution as well as particular aging measures across different intellectual acceptance periods.

In contrast with the general assumption that scholars in humanities disciplines make greater use of the books in their research than their fellow colleagues in science or social science disciplines do, the average book citation counts in religion and history were found to be the lowest among the six disciplines in the sample data. Psychology has the highest number of citations to its books. Monographs in psychology, mathematics, and physics have a statistically higher citation rate than those in religion, history, and economics. The sample data also contradicts the previous findings that suggested that scientific disciplines hold a shorter half-life than humanities' disciplines. In this study, the half-life for monographs in physics was found to be over 13 years, which is the longest among the disciplines. Such a statistic is over twice as long as the half-life values reported for physics journal literature. ${ }^{66}$ The shortest half-lives were history and psychology monographs. Interestingly, the half-lives of both humanities disciplines - history and religion-were found to be among the shortest ones.

The noncitation percentages of the six disciplines are all lower than those reported on uncitedness of journal literature. This confirms the previous research results that books in general receive a higher citation rate that journal articles. ${ }^{67}$ Monographs in history and religion were found to have the highest uncitedness ratios, which is consistent with Hamilton's results. ${ }^{6}$ Physics and psychology have the lowest uncitedness ratios in monographs, which is also consistent with Hamilton's statistics. Note that, in this study, the uncitedness was examined in a much longer period (in the case of economics, it was over 200 years) than Hamilton's data (four years). Comparatively speaking, the field of mathematics shows a high uncitedness proportion to both journal articles and books than other hard science disciplines do.

The data on Price's Index suggest that scientific disciplines, including physics and mathematics, have the highest scores of recency. Note that this is consistent with the previous findings of around 50 percent recent literature for science. On the other hand, the monographs in religion and history in this study sample have a higher recency percentage than the estimated 21 percent from the previous report. ${ }^{69}$ Among the six disciplines, history has the lowest level of recent citations, whereas the proportion of citation recency for religion is surprisingly high. This may indicate that a good portion of recent research in religion relies on monographs. Another surprise is that books in economics have the second lowest citation recency rate among the disciplines, but they reached their citation peak within the first year of publication. This confirms Line's results that economists use literature in a wide range of publication dates, including the most recent and extremely old sources. ${ }^{70}$

ANOVA and MANOVA statistical tests showed that not only the distributions of citations to monographs are different, discipline by discipline, but also the recency of the citations to monographs is different among the six disciplines. The most significant group contrasts suggest that religion, history, and economics share some similarities in monographic in-degree citations, whereas citation patterns of psychology, mathematics, and physics appear closely bound together as a group. The fact that psychology sides with scientific disciplines in their citation patterns, while economics moves along with humanities disciplines, 
may indicate some common scholarship qualities and research characteristics in the disciplines involved.

In this study, the field of psychology exhibits some interesting dynamics in its monographic citing behavior. Not only do psychology books receive the greatest number of citations, they also have a very low uncitedness ratio, a short half-life, and yet a relatively high citation recency percentage. From individual citation measures to results of statistical contrast tests, citations to psychology monographs have been proven to hold great affinity to citations to hard science monographs. This particular discovery reinforces Small and Crane's observation that the characteristics of citation distribution place psychology much closer to scientific disciplines than to the fields in social science. ${ }^{71}$ Further studies are needed to examine what specific aspects or sectors of psychology research draw the discipline closer to scientific scholarship than to disciplines in other domains.

In examining periods of acceptance for monographs, the statistical contrasts in MANOVA identified significant differences between disciplinary citation counts of initial three periods and the subsequent periods. This suggests that the highest potential period of intellectual acceptance is the first 10 years, with the decline and the gradual ending of citations during the 11th to 30th years or beyond following the original publication. A surprising result is that books from the humanities and economics aged rather quickly, whereas books in scientific disciplines and psychology did not reach their citation peak until well beyond six years. The immediate attention to books in history, religion, and economics may indicate that monographs are indeed an important part of scholarly communication in these disciplines. Meanwhile, the longer time required for books in psychology, physics, and mathematics to arrive at their primal attraction could suggest that journal articles are the major source of current literature in these disciplines while books generally require several years after they are in print to be fully appreciated.

The present study is one of the first studies that investigated the disciplinarybased citing behavior to monographic literature. Although limitations may be found in using the data generated from particular databases, those databases are considered the best possible source available online at the current time. Further investigations on disciplinary differences concerning the cross-disciplinary citations, the language aspect of the citation, and types of citation materials are currently under way. A full analysis of citations to scholarly monographs can only be obtained through combining the findings of this paper with all the mentioned aspects. A complete understanding of intellectual acceptance and survival of scholarly monographs may be achieved after all data are integrated and analyses are conducted in multiple dimensions to include multifaceted elements.

\section{Notes}

1. Maurice B. Line, "The Influence of the Type of Sources Used on the Results of Citation Analyses," Journal of Documentation 35, no. 4 (Dec. 1979): 265-84; Anton J. Nederhof, Rolf A. Zwaan, Renger E. de Bruin, and P.J. Dekker, "Assessing the Usefulness of Bibliomeric Indicators for the Humanities and the Social and Behavioural Science: A Comparative Study," Scientometrics 15, no. 5-6 (May 1989): 423-35; Diana Hicks and Jonathan Potter, "Sociology of Scientific Knowledge: A Reflexive Citation Analysis or Science Disciplines and Disciplining Science," Social Studies of Science 21, no. 3 (1991): 459-501; Blaise Cronin, Herbert W. Snyder, and Helen Barsky Atkins, "Comparative Citation Rankings of Authors in Monographic and Journal Literature: A Study of Sociology," Journal of Documentation 53, no.3 (June 1997): 263-73.

2. Cronin et al., "Comparative Citation Rankings"; Berenika Winclawska, "Polish Sociology Citation Index: Principles for Creation and the First Results," Scientometrics 35, no. 3 (1996): 387-91. 
3. Ylva Lindholm-Romantschuk and Julian Warner, "The Role of Monographs in Scholarly Communication: An Empirical Study of Philosophy, Sociology and Economics," Journal of Documentation 52, no. 4 (December 1996): 389-404.

4. Line, "The Influence of the Type of Sources," 266.

5. Karl J. Weintaub, "The Humanistic Scholar and the Library," Library Quarterly 50, no. 1 (1980): 22-39.

6. Ibid., 25.

7. Robert N. Broadus, "The Literature of the Social Sciences: A Survey of Citation Studies," International Social Science Journal 23 (1971): 236-43.

8. Penelope Earle and Brian Vickery, "Social Science Literature Use in the U.K. as Indicated by Citations," Journal of Documentation 25, no. 2 (1969): 123-41.

9. Henry G. Small and D. Crane, "Specialties and Disciplines in Science and Social Science: An Examination of Their Structure Using Citation Indexes," Scientometrics 1, no. 5/6 (1979): 445-61.

10. Susan Bonzi, "Trends in Research Productivity among Senior Faculty," Information Processing and Management 28, no. 1 (1992): 111-20.

11. Rose Mary Magrill and Gloriana St. Clair, "Undergraduate Term Paper Citation Patterns by Disciplines and Level of Course.," Collection Management 12, no. 3/4 (1990): 25-56.

12. Madeleine Stern, "Characteristics of the Literature of Literary Scholarship," College $\mathcal{E}$ Research Libraries 44, no. 4 (July 1983): 199-209.

13. Richard Heinzkill, "Characteristics of References in Selected Scholarly English Literary Journals," Library Quarterly 50, no. 3 (1980): 352-65.

14. John Cullars, "Characteristics of the Monographic Literature of British and American Literary Studies," College \& Research Libraries 46, no. 6 (Nov. 1985): 511-22.

15. John Budd, "Characteristics of Written Scholarship in American Literature: A Citation Study," Library E Information Science Research 8, no. 2 (Apr.-June 1986): 189-211.

16. B.R. Tucker, "Characteristics of the Literature Cited by Authors of the Transactions of the American Philosophical Association, 1956 and 1957" (master's thesis, University of North Carolina at Chapel Hill, 1959); Charles Avery Bolles, "Characteristics of the Literature of American studies as Indicated by Bibliographic Citations" (PhD diss., University of Minnesota, 1975).

17. Diana Hicks, "The Four Literatures of Social Science," in Handbook of Quantitative Social Science and Technology Research, ed. H.F. Moed, W. Glänzel, and U. Schmoch (Dordrecht: Kluwer Academic, 2004), 473-96. Available online from http://www.tpac.gatech.edu/papers/4lit.PDF. [Accessed 9 August 2007].

18. Ibid., 8 .

19. Line, "The Influence of the Type of Sources"; Lindholm-Romantschuk and Warner, "The Role of Monographs in Scholarly Communication"; Cullars, "Characteristics of the Monographic Literature of British and American Literary Studies."

20. Hicks and Potter, "Sociology of Scientific Knowledge."

21. Elisabeth S. Clemens, Walter W. Powell, Kris McILWaine, and Dina Okamoto, "Careers in Print: Books, Journals, and Scholarly Reputations," American Journal of Sociology 101, no. 2 (Sept. 1995): 433-94.

22. Lindholm-Romantschuk and Warner, "The Role of Monographs in Scholarly Communication."

23. Stern, "Characteristics of the Literature of Literary Scholarship."

24. Line, "The Influence of the Type of Sources."

25. Cronin, Snyder, and Atkins, "Comparative Citation Rankings," 269.

26. Hicks, "The Four Literatures of Social Science."

27. Virgil Diodato, Dictionary of Bibliometrics (New York: The Haworth Press, 1994).

28. D.J. de Solla Price, "Networks of Scientific Papers," Science 149, no. 3683 (July 1965): 510-15.

29. Eugene Garfield, "Citation Indexes in Information Retrieval," Journal of the American Society for Information Science 34, no. 4 (1983): 298-99.

30. David P. Hamilton, "Publishing by - and for? - the Numbers," Science 250, no. 4986 (Dec. 1990): 1331-32; John A. Tainer et al., "Science, Citation, and Funding," Science 251, no. 5000 (1991): 1408-11.

31. David P. Hamilton, "Research Papers: Who's Uncited Now?" Science 251 (1991): 25.

32. Diodato, Dictionary of Bibliometrics.

33. Earle and Vickery, "Social Science Literature Use in the U.K."

34. R.E. Burton and R.W. Kebler, "The 'Half-Life' of Some Scientific and Technical Literatures," American Documentation 11, no. 1 (1960): 18-22.; Usha Gupta, “Obsolescence of Physics Literature: Exponential Decrease of the Density of Citations to Physical Review Articles with Age," Journal of the American Society for Information Science 41, no. 4 (June 1990): 282-87.

35. Earle and Vickery, "Social Science Literature Use in the U.K." 
36. Stephen E. Wiberley, Jr., "A Methodological Approach to Developing Bibliometric Models of Types of Humanities Scholarship," Library Quarterly 73, no. 2 (Apr. 2003): 121-59.

37. Budd, "Characteristics of Written Scholarship."

38. D.J. de Solla Price, "Citation Measures in Hard Science, Soft Science, Technology and Nonscience," in Communication among Scientists and Engineers, ed. C.E. Nelson and D.K. Pollock. (Lexington, Mass.: Heath Lexington, 1970): 3-12.

39. Ibid.

40. Edwin B. Parker, Willam J. Paisley, and Roger Garrett, "Bibliographic Citations as Unobtrusive Measures of Scientific Communication" (Stanford, Calif.: Stanford University Institute for Communications Research, Oct. 1967), 125.

41. De Solla Price, "Citation Measures in Hard Science, Soft Science, Technology and Nonscience."

42. Budd, "Characteristics of Written Scholarship."

43. Budd, "Characteristics of Written Scholarship," 196.

44. Small and Crane, "Specialties and Disciplines in Science and Social Science."

45. Line, "The Influence of the Type of Sources."

46. Line, "The Influence of the Type of Sources," 271.

47. Lindholm-Romantschuk and Warner, "The Role of Monographs."

48. Lindholm-Romantschuk and Warner, "The Role of Monographs," 393.

49. Lindholm-Romantschuk and Warner, "The Role of Monographs."

50. L.R. Gay and Peter Airasian, Educational Research: Competencies for Analysis and Application, 7th ed. (Upper Saddle River, N.J.: Merrill/Prentice Hall, 2003).

51. Dialog Corporation, "LC MARC-Books Bluesheets" (Cary, N.C.: Dialog, 2006). Available online from http://library.dialog.com/bluesheets/html/bl0426.html. [Accessed 9 August 2007].

52. Dialog Corporation, "SciSearch Bluesheets," (Cary, N.C.: Dialog, 2006), available online from http://library.dialog.com/bluesheets/html/bl0034.html [Accessed 9 August 2007]; Dialog Corporation, "Social SciSearch Bluesheets," (Cary, N.C.: Dialog, 2006), available online from http://library. dialog.com/bluesheets/html/bl0007.html [Accessed 9 August 2007]; Dialog Corporation, "Arts \& Humanities Search Bluesheets," (Cary, N.C.: Dialog, 2006), available online from http://library. dialog.com/bluesheets/html/bl0439.html [Accessed 9 August 2007].

53. Cronin et al., "Comparative Citation Rankings"; Winclawska, "Polish Sociology Citation Index."

54. Berenika M. Winclawska, "Polish Sociology Citation Index: Principles for Creation and the First Results," Scientometrics 35, no. 3 (1996): 387-91; Thed N. Van Leeuwen, Henk F. Moed, Robert J.W. Tijssen, Martijn S. Visser, and Anthony F.J. Van Raan, "First Evidence of Serious Language-Bias in the Use of Citation Analysis for the Evaluation of National Science Systems," Research Evaluation 8, no. 2 (2000): 155-56.

55. Lindholm-Romantschuk and Warner, "The Role of Monographs."

56. Ibid.

57. Earle and Vickery, "Social Science Literature Use in the U.K."

58. De Solla Price, "Citation Measures in Hard Science, Soft Science, Technology and Nonscience."

59. Hamilton, "Research Papers: Who's Uncited Now?"

60. Ibid.

61. Ibid.

62. Ibid.

63. Clemens et al., "Careers in Print: Books, Journals, and Scholarly Reputations."

64. Line, "The Influence of the Type of Sources."

65. Hicks and Potter, "Sociology of Scientific Knowledge."

66. Burton and Kebler, "The 'Half-Life' of Some Scientific and Technical Literatures"; Gupta, "Obsolescence of Physics Literature."

67. Hicks and Potter, "Sociology of Scientific Knowledge"; Lindholm-Romantschuk and Warner, "The Role of Monographs"; Clemens et al., "Careers in Print: Books, Journals, and Scholarly Reputations."

68. Hamilton, "Research Papers: Who's Uncited Now?"

69. De Solla Price, "Citation Measures in Hard Science, Soft Science, Technology and Nonscience."

70. Line, "The Influence of the Type of Sources."

71. Small and Crane, "Specialties and Disciplines in Science and Social Science."

72. Hamilton, "Research Papers: Who's Uncited Now?" 